\title{
ENTRE CONGRUÊNCIAS E INCONGRUÊNCIAS DO METATERMO LUSOFONIA
}

\section{RICARDO FRANCISCO NOGUEIRA VILARINHO*}

Pontifícia Universidade Católica de São Paulo (PUC-SP), Programa de Estudos Pós-Graduados em Língua Portuguesa (PEPGLP), São Paulo, SP, Brasil.

Recebido em: 13 jan. 2020. Aprovado em: 17 fev. 2021.

Como citar este artigo: VILARINHO, R. F. N. Entre congruências e incongruências do metatermo Iusofonia. Cadernos de Pós-Graduação em Letras, v. 21, n. 1, p. 248-260, jan./abr. 2021. doi: 10.5935/ cadernosletras.v21n1p248-260

\section{Resumo}

Neste artigo partimos de dois textos, Faraco (2012) e Arakaki e Bastos (2016), extraindo deles as definições de lusofonia dos linguistas Carlos Alberto Faraco, José Luiz Fiorin, Armando Jorge Lopes, Eliseu Mabasso e Moisés de Lemos Martins. Como ferramenta de análise, utilizamos a teoria matemática dos conjuntos e, da geometria, apropriamo-nos dos conceitos de congruência e incongruência de ângulos. Dessa forma, ao final, concluímos que ambos os linguistas descrevem o mesmo fenômeno, observado por perspectivas diferentes, conforme descrito por Kuhn (2018).

* E-mail: nogueiravilarinho@gmail.com

(D) https://orcid.org/0000-0002-7634-3558 


\section{Palavras-chave}

Lusofonia. Filosofia da linguística. Análise linguística.

\section{QUIMERAS E POSSIBILIDADES}

Neste artigo partimos de dois textos, Faraco (2012) e Arakaki e Bastos (2016), ${ }^{1}$ extraindo deles as definições de lusofonia para cinco linguistas, são eles: Carlos Alberto Faraco, José Luiz Fiorin, Armando Jorge Lopes, Eliseu Mabasso e Moisés de Lemos Martins. A princípio, o que nos motivou a escrevê-lo foi a sensação de que Faraco (2012) provocou em alguns pesquisadores que se dedicam a estudar a lusofonia um certo desconforto, um certo mal-estar, com relação ao seu objeto de estudo, ou seja, a própria lusofonia, objeto polissêmico, multifacetado. Dessa forma, decidimos buscar os pontos nos quais as definições extraídas dos linguistas citados se distanciariam ou se aproximariam. Para isso, utilizamos a representação geométrica de congruência e incongruência, conforme assim as define a matemática, e também nos apropriamos das propriedades matemáticas da intersecção de conjuntos.

Em uma leitura inicial, observamos que o ponto de vista dos linguistas não é totalmente incongruente, porém Faraco (2012) é mais enfático ao comparar a lusofonia a uma quimera, mero ideal. Acreditamos estar aí o cerne da discórdia, pois, ao materializar a impossibilidade de realização, que passaremos a chamar de "não realização" de um objeto teórico, o linguista desautoriza os pesquisadores que se dedicam a pensar a lusofonia.

Mesmo supondo que uma tal LUSOFONIA seja possível (e desejável) e se possa delineá-la para além de generalidades, sobrará ainda um segundo grande dilema para Portugal - o da língua propriamente dita, ou seja, o que fazer com o Brasil numa comunidade de países lusófonos: como evitar que a língua, embora de nome portuguesa, fique identificada, de fato, com o país que congrega a maioria absoluta de seus falantes? Como evitar que a presença da indústria cultural brasileira nos meios de comunicação social de todos os países de língua oficial portuguesa termine por brasilianizar a língua? (FARACO, 2012, p. 47, grifo nosso).

1 Em Arakaki e Bastos (2016), buscaremos as definições de quatro linguistas: José Luiz Fiorin, Armando Lopes, Eliseu Mabasso e Moisés Martins. 
Como podemos observar, Faraco (2012) escancara e problematiza as dificuldades enfrentadas no estabelecimento da lusofonia como campo de estudo. No texto já citado, intitulado "Lusofonia: utopia ou quimera? Língua, história e política”, Faraco (2012) destaca a impossibilidade de realização da lusofonia com o auxílio de dois termos: utopia e quimera, ambos contidos no título do texto. Pela leitura do título, apenas, observamos que a definição do autor aponta para um polo do "não realizável". Tanto quimera quanto utopia estão no campo do desejo, são construções de um ideal não realizável.

Como justificativa de sua construção, afirma, que, na verdade, o que, a princípio, estabelece-se como lusofonia passaria, inevitavelmente, a uma "brasilofonia", em razão da pujança da indústria cultural brasileira.

Sendo assim, buscamos nos textos pontos importantes na construção das definições do sentido de lusofonia para os autores. Como ferramenta de análise, utilizamos a teoria matemática dos conjuntos, sobretudo a ideia de intersecção, e, da geometria, apropriamo-nos dos conceitos de congruência e incongruência de ângulos. Também como sustentáculo teórico de nosso modelo de análise, utilizamos as ideias de Kuhn (2018), Feyerabend (2011) e Henry (1992).

\section{REFLEXÕES INICIAIS}

Para dar início às nossas reflexões, apropriamo-nos das definições de Faraco (2012, p. 32), que afirma:

LUSOFONIA, como dissemos, é um termo polissêmico. Ora é usado para fazer referência ao conjunto dos falantes de português mundo afora - diz-se, portanto, da população lusófona. Um uso descritivo, que recorta uma determinada quantidade e, aparentemente, não carrega maiores implicações políticas ou valorativas.

A essa primeira definição, o autor nos faz refletir sobre as características geográficas da territorialidade da língua portuguesa, melhor dizendo, o conjunto de falantes que usam a língua portuguesa. Podemos ampliar essa perspectiva, buscando a visão do linguista Eliseu Mabasso, de acordo com Arakaki e Bastos (2016, p. 83, grifo nosso): 
Assim, primeiramente, mencionamos Eliseu Mabasso que, em seu depoimento, assevera haver vários fatores a serem considerados quando se associa o conceito de "lusofonia" ao conjunto de todas as comunidades onde se fala a Língua Portuguesa, ou seja, o mundo lusófono ou mundo da lusofonia.

A afirmação do linguista moçambicano chama-nos a atenção sobretudo ao que acrescenta a definição extraída de Faraco (2012), a preocupação com vários fatores que devem ser analisados quando nos apropriamos da definição geográfica do termo lusofonia. Sendo assim, estamos de acordo que o termo lusofonia é polissêmico, que representa o conjunto de falantes de língua portuguesa espalhados pelo mundo. Porém, é de suma importância a ponderação de Eliseu Mabasso que nos faz refletir sobre os vários fatores que norteiam essa definição.

Ou seja, parece ser consenso que o termo lusofonia, quando despido das implicações políticas e valorativas, representa o conjunto de falantes de língua portuguesa. Quanto a esse ponto parece não haver dúvidas.

É também de Arakaki e Bastos (2016) que retiramos o conceito de Eliseu Mabasso de círculo de expansão e de círculo interior. Para o linguista, o português europeu (PE) e o português brasileiro (PB) ocupariam a parte interior, e os demais países seriam todos frutos dessa expansão da língua portuguesa. Portanto, de acordo com o linguista, o Brasil ocupa uma posição nem de inferioridade, nem de superioridade, mas uma posição de igualdade; sendo assim, o Brasil, ex-colônia, coloca-se em um locus de igualdade em relação ao colonizador. A criatura chega ao nível do criador.

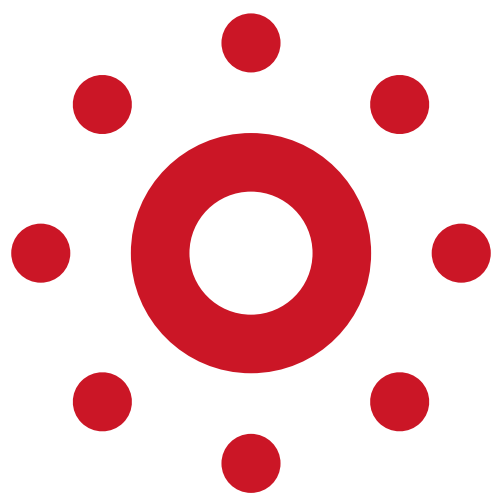

Figura 1 - Círculos de Eliseu Mabasso. 
A figura ilustra os círculos propostos por Eliseu Mabasso. O conjunto interior representa o PE e o PB. Já o conjunto externo engloba os outros países lusofalantes. É interessante destacar que para o linguista não há hierarquia entre o PE e o PB. Essa ideia, a nosso ver, corrobora as ponderações de Faraco (2012), pois, segundo o autor, apesar de estarem no mesmo patamar, o PB frustraria a ideia de construção de uma lusofonia em razão da importância da indústria cultural do Brasil.

Sobre essa suposta igualdade de importância e suas consequências, em Faraco (2012) encontramos o conceito do fenômeno de "brasilianização" da língua portuguesa, que representa a disputa político-linguística existente entre os países do círculo interior, melhor dizendo, Brasil e Portugal.

Acreditamos que explorar as definições de lusofonia partindo do conceito de Eliseu Mabasso de círculo interior e círculo de expansão fará, em um próximo trabalho, com que possamos delinear as definições de cultura e identidade lusófona.

\section{SOBRE A METODOLOGIA}

O uso da matemática como ferramenta de análise ou representação nas ciências humanas não é algo novo. Com relação à nossa produção, baseamo-nos na construção teórica de Jacques Lacan (1901-1981) e no uso da topologia como forma de representação para alicerçarmos a metodologia utilizada neste trabalho. Enfatizamos que o uso dos recursos topológicos foi pensado, nas ciências humanas, primeiramente pelo psicanalista, como informa Granon-Lafont (1990, p. 19): "Cabe a Lacan todo o mérito de ter procurado traçar os contornos desta especificidade da topologia e de indicar qual poderia ser seu uso nas ciências humanas". Também Agustini (1999) usa a geometria em um apêndice de sua dissertação de mestrado, intitulada Dobras interdiscursivas: o movimento do sujeito na construção enunciativa dos sentidos, para definir o que ela chama de Faixa de Möbius. Especificamente sobre a topologia da Banda de Moébius, já discutimos em Vilarinho (2012) as especificidades teóricas dessa figura topológica e seu uso nas ciências humanas. Neste trabalho, particularmente, utilizaremos as propriedades da intersecção de conjuntos e as definições de congruência e incongruência extraídas de Aurélio (2014). Sobre congruência diz-se das figuras geométricas que têm o mesmo tamanho e a mesma forma, pois os ângulos e os lados correspondentes são iguais. Como 
definição de incongruência podemos citar as relações opostas, ou seja, figuras geométricas que têm tamanhos distintos e formas distintas.
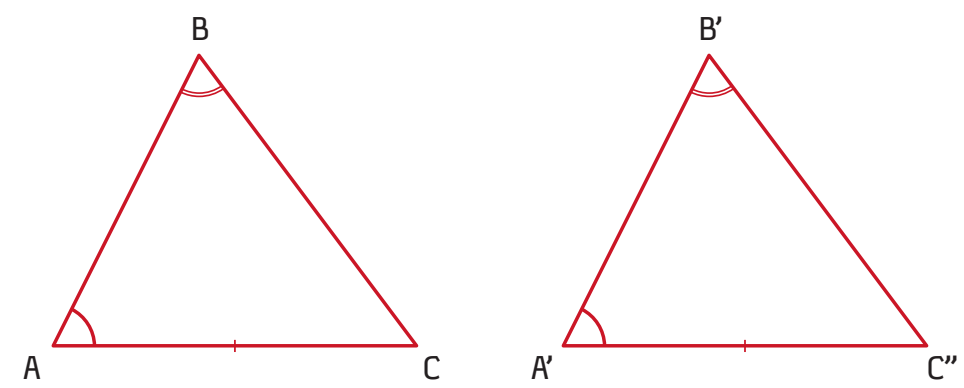

Figura 2 - Dois triângulos com ângulos congruentes.

Fonte: Thomé (2019).

Dessa forma, como B = B', A = A' e C = C', podemos afirmar que os ângulos dos dois triângulos são congruentes, pois têm a mesma medida. Neste trabalho, buscamos nos textos dos linguistas analisados as congruências e incongruências dos discursos que se referem à definição do termo lusofonia. Por meio da análise apenas do título do texto de Carlos Faraco, poderíamos já, de imediato, classificar o texto desse autor apontando para o polo da "não realização" da lusofonia. Os termos quimera e utopia apontam para esse sentido.

Podemos considerar o uso da matemática como ferramenta de análise e representação de fenômenos linguísticos como parte de uma epistemologia da linguística que busca metodologias inovadoras. ${ }^{2}$ Por exemplo, o uso da topologia e especificamente o uso da Banda de Moébius para representação do sujeito em oposição ao sujeito cartesiano dicotomizado, que em muitas teorias é pensado como um sujeito que cabe dentro de um interno e um externo. Há teorias que ainda pensam e defendem que o sujeito é dicotomizado (macho/fêmea, homem/mulher, bem/mal), e sua plenitude estaria inserida em um ideal de completude. Com o auxílio da matemática e da topologia, podemos representar conceitos e ideias congruentes e incongruentes, ou seja, tanto um sujeito dicotomizado como um sujeito que subverte a estrutura polarizada. ${ }^{3}$ Para representação do sujeito não dicotomizado, faz-se necessário recorrer à topologia.

2 Feyerabend (2011) nos anima a praticar um certo anarquismo metodológico, que, segundo ele, funciona com remédio para a epistemologia e para a filosofia da ciência.

3 A geometria euclidiana não fornece uma estrutura de representação que abarque todas as nuances da complexidade do sujeito. 


\section{MESMO OBJETO, VISÕES DIFERENTES}

Podemos também, em uma outra perspectiva, pensar a lusofonia como fenômeno observado de maneiras diversas pelos linguistas estudados. Dessa forma, as definições do termo estariam contidas em uma área limitada por polos ${ }^{4}$ cujos vértices encontram-se na "realização" ou "não realização". Da mesma maneira, as definições, em uma representação por conjuntos, estariam contidas dentro dos campos “A" e "B", e a área em destaque corresponderia à intersecção das definições, melhor dizendo, as definições nessa área apontam para a congruência, para a similaridade.

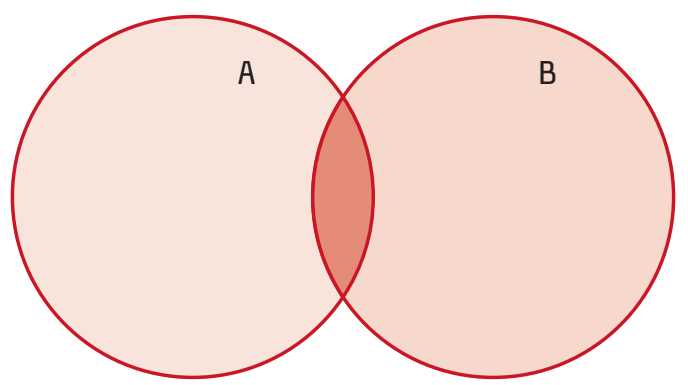

Figura 3 - Os conjuntos "A" e "B" possuem uma área em comum que utilizamos para representar a congruência nas definições do termo lusofonia.

A leitura de Kuhn (2018, p. 156-157, grifo nosso), principalmente no tópico que trata as revoluções como mudanças, chamou-nos a atenção para possibilidades de visualização de um mesmo objeto de maneiras distintas:

Nenhum desses temas promotores de crises produziu até agora uma alternativa viável para o paradigma epistemológico tradicional, mas já começaram a sugerir quais serão algumas das características desse paradigma. Estou, por exemplo, profundamente consciente das dificuldades criadas pela afirmação de que, quando Aristóteles e Galileu olharam para as pedras oscilantes, o primeiro viu uma queda violenta e o segundo um pêndulo. As mesmas dificuldades estão presentes de uma forma ainda mais fundamental nas frases iniciais deste capítulo: embora o mundo não mude com uma mudança de paradigma, depois

4 A ideia de representação de um fenômeno por polos retiramos de Henry (1992) que afirma que a linguística emergiu de uma conjuntura científica e ideológica cujos eixos podem ser descritos. 
dela o cientista trabalha em um mundo diferente. Não obstante, estou convencido de que devemos aprender a compreender o sentido de proposições semeIhantes a essa. 0 que ocorre durante uma revolução científica não é totalmente redutível a uma reinterpretação de dados estáveis e individuais.

Conforme observado pelo autor, os dois filósofos descreveram o mesmo fenômeno de maneira diferente. Assim, as definições do termo lusofonia extraídas dos dois textos analisados trazem as concepções dos cinco linguistas estudados e suas definições que ora apontam para uma total incongruência, ora para uma possibilidade de congruência. Sendo assim, passamos a considerar a possibilidade de que os textos falavam de um mesmo fenômeno, porém com pontos de vista diferentes. Nesse caminho, a leitura de Kuhn (2018), que se centra na descrição do ambiente científico pré e pós-mudança de um paradigma, foi de extrema importância para nossas análises. Diferentemente do autor citado, em nosso texto não está em discussão a mudança de um paradigma linguístico ou da política linguística que se refere às relações entre os povos lusofalantes. Porém, tendemos a pensar que o surgimento de um novo paradigma, assim como o foco em qualquer um dos polos já citados, ou seja, a realização e não realização da lusofonia, faz com que aconteça um desvio no olhar de quem observa. No dizer de Kuhn (2018, p. 145, grifo nosso), "Guiados por um novo paradigma, os cientistas adotam novos instrumentos e orientam seu olhar em novas direções". Sendo assim, observamos que as diferenças contidas nas definições estudadas centram-se nas diferenças dos focos de observação. Para Faraco (2012), a lusofonia não se realiza, é mera idealização. Porém, para os linguistas citados por Arakaki e Bastos (2016), não há dúvidas com respeito à existência da lusofonia. As críticas estão na maneira como os sujeitos constituem/formam o mundo lusófono.

\section{ENTRE CONGRUÊNCIAS E INCONGRUÊNCIAS: NOSSAS ANÁLISES}

Partindo de algumas topicalizações, analisamos semelhanças e diferenças do pensamento dos linguistas citados.

- (1) Lusofonia é diferente de anglofonia e francofonia e assemelha-se a hispanofonia. 
Encontramos esse posicionamento em Faraco (2012, p. 36) que afirma:

Das quatro analisadas, a LUSOFONIA, de certa forma, é a mais tardia e, talvez, a mais complicada e frágil de todas. Atrás dela não há, como na anglofonia e na francofonia, uma ex-metrópole colonial que tenha sido, no século 20, uma potência política, militar e econômica. Não há, portanto, um grande projeto estratégico de natureza política, econômica e cultural.

Nesse ponto, o linguista aproxima lusofonia e hispanofonia e as distancia da anglofonia e da francofonia. Esse distanciamento coloca o pensamento de Faraco em uma posição de incongruência quando a cotejamos com a perspectiva de círculo interior e círculo de expansão proposta por Mabasso, pois, de acordo com o linguista moçambicano, Brasil e Portugal fazem parte do círculo interior. Dessa forma, Estados Unidos e Inglaterra ocupariam o mesmo lugar que os países citados, melhor dizendo, na perspectiva dos círculos não há diferença entre anglofonia e lusofonia.

O ponto de vista amplo de José Luiz Fiorin, citado por Arakaki e Bastos (2016), é totalmente congruente com a definição de Faraco (2012), pois, para ambos, há uma impossibilidade de realização da concretização de um projeto de lusofonia. Fiorin considera que Portugal e Brasil já estão comprometidos com entidades transnacionais maiores, respectivamente a União Europeia e o Mercosul, sendo assim não há como se falar em lusofonia a não ser em um ponto de vista restrito, melhor dizendo, apenas como conjunto de países que adotam o português como língua oficial.

O pensamento de Armando Lopes é também no sentido de uma impossibilidade de realização de um projeto de lusofonia, ou seja, é congruente com o de Faraco (2012), pois para o primeiro o paradigma colonial ${ }^{5}$ impossibilita a realização de um projeto de unidade lusófona.

- (2) A questão do gênero.

Chamou-nos a atenção o posicionamento do linguista Armando Lopes e sua crítica com relação à participação das mulheres nas discussões sobre a lusofonia. Esse ponto foi abordado apenas por esse linguista, porém, se anali-

5 Recomendamos a leitura de Arakaki e Bastos (2016) e sua proposta de análise esmiuçada do depoimento de quatro intelectuais do espaço lusófono. $\mathrm{O}$ artigo apresenta, de forma detalhada, o posicionamento dos linguistas citados neste texto. 
samos as discussões propostas por Faraco (2012, p. 40, grifo nosso), encontramos a seguinte afirmação:

Talvez não seja equívoco dizer, então, que esse tema, quando ocorre aqui no Brasil, está restrito ao meio acadêmico. A literatura portuguesa e as literaturas africanas de língua portuguesa têm seu lugar nas universidades brasileiras. É neste contexto que, eventualmente, o tema aparece. E a compreensão de LUSOFONIA que predomina, neste caso, é o de uma realidade fundamentalmente linguístico-cultural, ou seja, a LUSOFONIA é entendida como o eixo que agrega literaturas e culturas que se expressam em português.

Achamos importante a relação estabelecida por Carlos Alberto Faraco entre lusofonia e cultura, pois, apesar de não estar explícita a questão do gênero, acreditamos que a lusofonia pensada com a questão cultural é um campo no qual o ideal de Armando Lopes pode ser cultivado. Sendo assim, pensar a questão cultural dos países lusofalantes permitiria discussões com relação aos atores sociais, falantes de português, e às suas culturas, seguramente impregnadas de uma prevalência do homem em uma posição privilegiada e da mulher em posição estigmatizada.

- (3) Sobre a dicotomia poder hard e poder soft.

Extraímos de Faraco (2012) o conceito de poder hard e poder soft. De acordo com o linguista,

Nesse processo, paralelo ao exercício do poder "hard" (com o controle político, militar e econômico dos territórios submetidos), nasciam os primeiros delineamentos do chamado poder "soft", que se fundava justamente numa pretensa unidade cultural dada por uma língua comum portadora da civilização que vencia a barbárie (FARACO, 2012, p. 33).

Dessa forma, interessa-nos refletir sobre a intersecção entre a dicotomia hard e soft e a dicotomia dos círculos, interior e de expansão, conforme teorizado por Eliseu Mabasso.

Enfatiza a importância dos chamados países do Círculo de Expansão que que "têm a particularidade de verem o Português a ser falado e ensinado nos seus territórios, sem que, necessariamente, tenha tido laços coloniais com Portugal” e, ainda, menciona os chamados países do Círculo Interior - Portugal e Brasil - 
cuja variedade está aceita nas comunidades em que se estudam as características linguísticas do PE e do PB (ARAKAKl; BASTOS, 2016, p. 83, grifos nossos).

Historicamente, Portugal, do círculo interior, é o único país a exercer o poder hard em relação aos outros países da Comunidade dos Países de Língua Portuguesa (CPLP). Nessa mesma linha, também foi o único a exercer o poder soft, pois foi o único que colonizou. Porém, ampliando o conceito de "poder soft", podemos afirmar que o Brasil hoje é o país que mais lucra com o estabelecimento e a manutenção do poder soft, pois tem uma indústria cultural estruturada que se beneficia com a unificação linguística de todos os países da comunidade. Melhor dizendo, apesar de ocupar o mesmo lugar que Portugal no círculo interior, superou o colonizador no que diz respeito à expansão da indústria cultural.

\section{CONSIDERAÇÕES FINAIS}

Buscamos neste texto refletir sobre as congruências e incongruências de cinco linguistas, Carlos Alberto Faraco, José Luiz Fiorin, Armando Jorge Lopes, Eliseu Mabasso e Moisés de Lemos Martins, com respeito às suas definições sobre o metatermo lusofonia. Com exceção de Carlos Alberto Faraco, cujo pensamento extraímos de Faraco (2012), as definições dos outros quatro linguistas foram extraídas de Arakaki e Bastos (2016). Para nossas análises, propusemos como ferramentas de análise as propriedades matemáticas da congruência e incongruência das figuras geométricas e a intersecção de conjuntos.

Dessa forma, concluímos que, apesar de parecerem, a princípio, diametralmente opostas, melhor dizendo, totalmente incongruentes, as definições de Carlos Alberto Faraco e dos demais linguistas estudados têm seus pontos de congruência e de incongruência, porém, vale destacar que apenas a análise do título proposto por Carlos Alberto Faraco - sua menção à utopia e à quimera pode gerar um estranhamento da compreensão de suas definições. Poderíamos apenas classificá-la como uma definição que apontaria para o polo da "não realização", da impossibilidade de concepção da lusofonia. Após uma leitura cuidadosa das concepções dos linguistas, concluímos que trata-se de um mesmo fenômeno observado, porém com pontos de vista diferentes, na trilha aberta por Kuhn (2018). Ao final, encontramos congruências e incongruências, semelhanças e diferenças nas várias definições do termo lusofonia estudadas. 


\section{Between congruences and incongruences of the metaterm Lusophony}

\section{Abstract}

In this article, we extract from Faraco (2012) and Arakaki and Bastos (2016) the definitions of Lusophony, according to Carlos Alberto Faraco, José Luiz Fiorin, Armando Jorge Lopes, Eliseu Mabasso, and Moises de Lemos Martins. As a tool of analysis, we use the mathematical theory of sets and geometry, the concepts of congruence and incongruence. Thus, in the end, we conclude that both linguists describe the same phenomenon, observed from different perspectives, as described by Kuhn (2018).

\section{Keywords}

Lusophony. Philosophy of linguistics. Linguistic analysis.

\section{REFERÊNICIAS}

AGUSTINI, C. L. H. Dobras interdiscursivas: o movimento do sujeito na construção enunciativa dos sentidos. 1999. Dissertação (Mestrado em Linguística) - Universidade Estadual de Campinas, Campinas, 1999.

ARAKAKI, N.; BASTOS N. B. Cultura, lusofonia e identidade: relações. In: BRIDI, M.; BRITO, R.; BASTOS N. (org.). Múltiplos olhares sobre lusofonia: Brasil, Moçambique e Portugal. São Paulo: Terracota, 2016. p. 65-98.

AURÉlIO, B. F. de H. Novo dicionário Aurélio da língua portuguesa. Curitiba: Positivo. 2014.

FARACO, C. A. Lusofonia: utopia ou quimera? Língua, história e política. In: LOBO, T. et al. (org.). Rosae: linguística histórica, história das línguas e outras histórias. Salvador: Edufba, 2012. p. 31-50. Disponível em: http://books.scielo.org/id/67y3k. Acesso em: 5 abr. 2021.

FEYERABEND, P. K. Contra o método. São Paulo: Editora Unesp, 2011.

GRANON-LAFONT, J. A topologia de Jacques Lacan. Rio de Janeiro: Jorge Zahar Editor, 1990.

HENRY, P. A ferramenta imperfeita. Língua, sujeito e discurso. Campinas: Editora da Unicamp, 1992. 
KUHN, T. S. A estrutura das revoluções científicas. São Paulo: Perspectiva, 2018.

THOMÉ, V. W. Visualização do caso de congruência lado, ângulo, ângulo oposto. Disponível em: https://pt.wikipedia.org/wiki/Ficheiro:Caso_de_congruencia_lado_ angulo_angulo_oposto.jpg. Acesso em: 23 jun. 2019.

VILARINHO, R. F. N. O interno e externo das teorias linguísticas e a banda de Moébius. Entreletras, Araguaína, v. 3, n. 1, p. 185-194, jan./jul. 2012. 